\title{
(3) castreser \\ Pushing beyond the limit: a novel clinical sign of thoracic aortic dissection
}

\author{
Thomas Meredith, Pankaj Jain, Michael Feneley
}

Department of Cardiology, St Vincent's Hospital, Sydney, New South Wales, Australia

Correspondence to Dr Thomas Meredith, tom.meredith@gmail.com

Accepted 7 November 2017
CrossMark

To cite: Meredith T, Jain $P$, Feneley M. BMJ Case Rep Published Online First: [please include Day Month Year]. doi:10.1136/bcr-2017 221653

\section{SUMMARY}

The timely diagnosis of aortic dissection is notoriously confounded by unreliable symptomatology. We present a previously unreported clinical sign: thoracic pain reproduced by abdominal palpation. Our case illustrates the dependence of traditional clinical features on the anatomical location of an aortic dissection and lends weight to the concept of aortic pain as being a dynamic product of inter-related changes in intraluminal pressure, volume, wall stress and diameter. The clinical sign we describe may be very specific of acute aortic pathology.

\section{BACKGROUND}

The prompt recognition of acute aortic dissection is key to optimising outcomes of what is the most common lethal aortic pathology, ${ }^{1}$ though the ability to do so is notoriously confounded by unreliable symptomatology and lack of reproducible, sensitive clinical signs. The tearing pleuritic chest pain of aortic dissection has been well described, but clinical examination findings are seldom contributory to the diagnosis of aortic syndromes, ${ }^{12}$ which relies principally instead on echocardiography and CT imaging. Here, we present a clinical case demonstrating a novel sign of thoracic aortic dissection: thoracic pain reproduced by abdominal palpation.

\section{CASE PRESENTATION}

A 53-year-old man with untreated hypertension presented to our emergency department complaining of acute chest pain of 30 minutes duration. He described the sudden onset of pleuritic anterior chest pain radiating to his back and throat with associated transient left arm paraesthesia. He did not report any preceding symptoms. He reported ongoing pain despite administration of intravenous morphine and sublingual glyceryl trinitrate on arrival. He took no regular medications. He had never smoked, drank minimal amounts of alcohol and denied illicit substance use.

Examination revealed a thin male in visible discomfort. His heart rate was $60 \mathrm{bpm}$, blood pressure $170 / 100 \mathrm{~mm} \mathrm{Hg}$ and $155 / 100 \mathrm{~mm} \mathrm{Hg}$ on the left and right arm, respectively, with normal oxygen saturations and respiratory rate. There were no features of Marfan syndrome. Radial pulses were equal in volume bilaterally and there was no radial-radial delay. Heart sounds were dual with no murmurs nor carotid bruits, and his lung fields were clear to auscultate. The neurological examination was unremarkable.
Examination of the abdomen was performed with the patient in the supine position with arms resting at his sides to relax the rectus muscles. On light manual palpation, his abdominal aorta was easily appreciated, though it was not distensible to suggest aneurysmal dilation. On deeper palpation in the central abdomen over the abdominal aorta, the patient described immediate and reliable reproduction and exacerbation of his chest pain.

\section{INVESTIGATIONS}

ECG revealed sinus rhythm with a normal cardiac axis and no features of ischaemia or conduction delay. A chest X-ray was unremarkable. An urgent transthoracic echocardiogram revealed normal biventricular size and systolic function without evidence of a proximal aortic dissection flap, aortic incompetence or pericardial effusion.

An urgent contrast CT aortogram revealed a Stanford Type A dissection (figure 1) originating immediately proximal to the brachiocephalic trunk (figure 2), and terminating immediately distal to the left subclavian artery (figure 3 ). There was a small periaortic haematoma but no false luminal exit tear or aneurysmal dilation. There was no involvement of the abdominal aorta.

\section{TREATMENT}

The patient was taken urgently to the operating theatre, where a proximal intimal tear correlating with the CT findings was identified. A hemi-arch repair was performed with the distal anastomosis of the graft placed just proximal to the left subclavian artery. He thereafter made an uneventful recovery.

\section{DISCUSSION}

Intimal tearing and propagation of blood flow between the aortic intima and media, the process which characterises aortic dissection, most commonly manifests as abrupt and severe pain, which is localised to the chest in $72.7 \%$ of patients. ${ }^{1}$ Despite the classic description of aortic dissection pain as being 'tearing' in nature, this sensation is variably reported in $6 \%-50 \%$ of patients with the disease. ${ }^{12}$ Moreover, the associated physical examination findings seen in aortic dissection carry limited diagnostic value; Hagen et al found hypertension to be the most frequent feature, which was still only present in $49 \%$ of patients, while a pulse deficit is observed in merely $15.1 \%{ }^{1}$ and neurological signs in $17 \% .^{1}$ The 


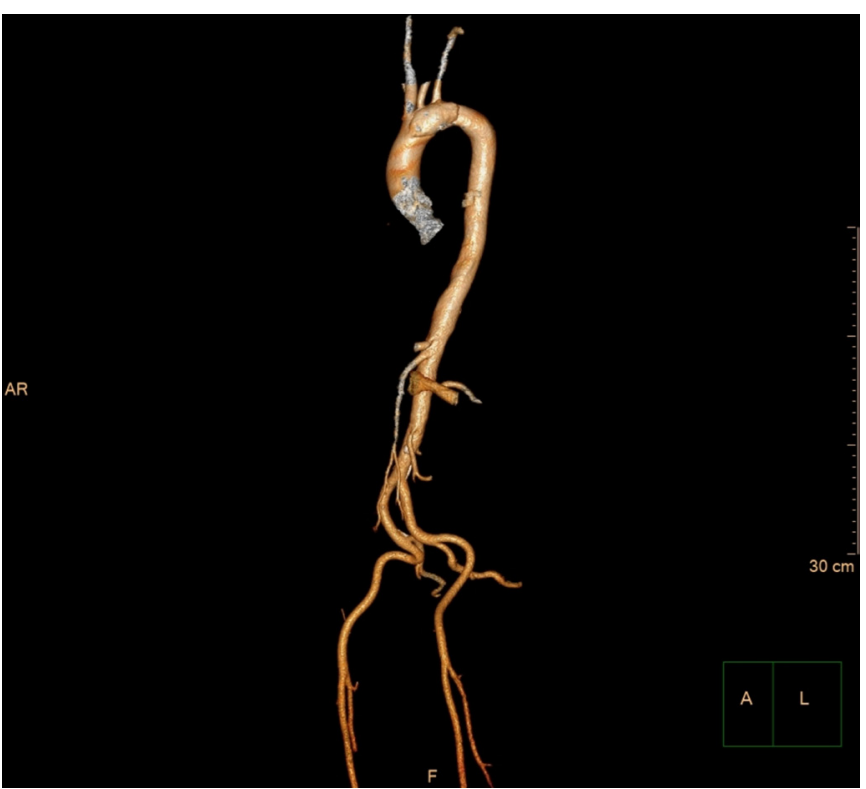

Figure 1 Three dimensional CT reconstruction of the Stanford type A dissection.

variability in clinical presentation is predominantly dictated by the location of intimal tear origin, the extension of the false lumen and disruption of side branches. The location of pain has been shown to correlate with the site and type of dissection, ${ }^{12}$ though no single sign has a predictive value powerful enough to make a certain diagnosis on clinical grounds alone.

Our case illustrates the dependence of traditional clinical features on anatomical location. Notably, the great vessels were all supplied by the true lumen, accounting for the absence of a pulse deficit or significant blood pressure differential between arms. Contradictory to the literature, in which hypertension is more frequently reported in distal rather than proximal dissections, ${ }^{1}$ our patient was indeed hypertensive, though the absence of retrograde extension to the aortic root or coronary vessels likely accounts for this, and also for the lack of ECG or echocardiographic findings.

The particular anatomy of the dissection in this case may also explain our previously unreported clinical finding of reproducible thoracic pain elicited through palpation of an

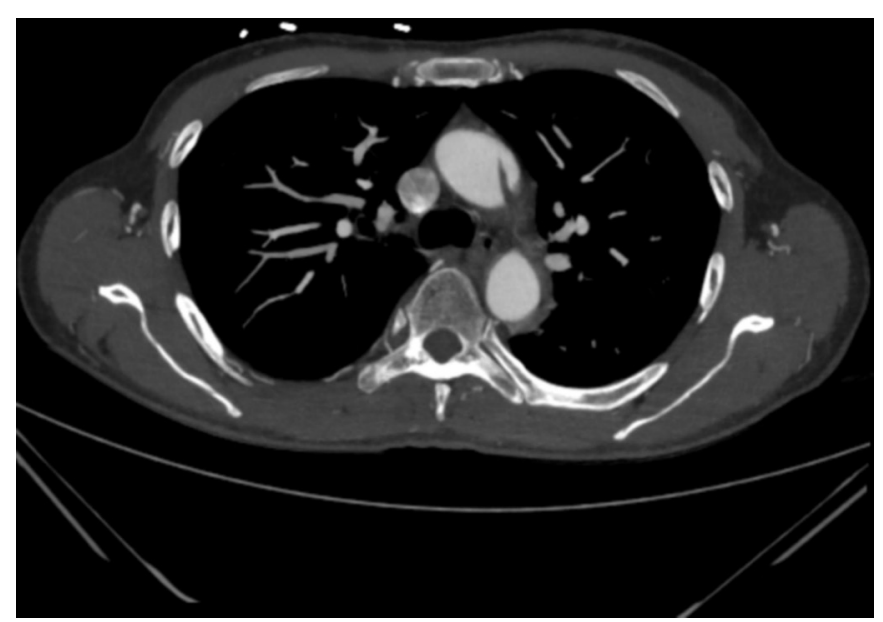

Figure 2 Axial CT image illustrating dissection origin, just proximal to the brachiochephalic trunk.

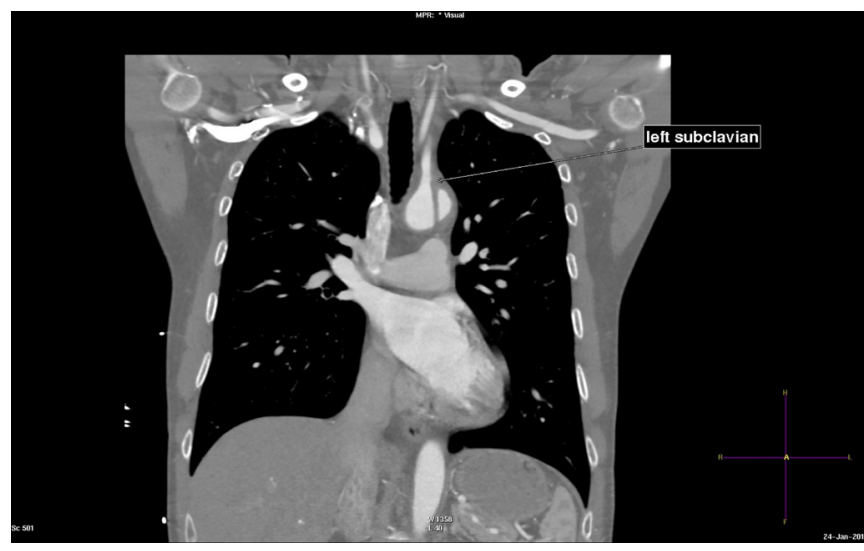

Figure 3 Coronal CT image demonstrating distal extent of dissection, being just distal to the left subclavian artery (arrow).

uninvolved abdominal aorta. With regard to the underlying pathophysiological mechanism, we postulate that mechanical compression of the abdominal aorta by deep palpation transiently increased afterload and, as a consequence, thoracic aortic wall stress. Another factor contributing to this mechanism may have been the absence of an exit tear. In this setting, increased afterload and therefore increased pressure within the false lumen may have resulted in expansion of false lumen diameter, resulting in an exacerbation of aortic pain.

In support of this hypothesis, it has been reported that the size and location of entry and exit tears determine the quantity of blood flowing into the false lumen, and that increased flow in the false lumen can cause aortic expansion. ${ }^{3}$ Moreover, Karmonik et al recently demonstrated that using simulated computational fluid dynamics that false lumen outflow restrictions, such as that caused by thrombosis, may increase false lumen pressure and aortic diameter. ${ }^{4}$ A neurosurgeon's personal experience of aortic dissection, in which he describes sudden and severe suprascapular pain that was 'pulsating slowly, varying from great intensity to negligible, in a cyclical manner' that corresponded to his heart rate, ${ }^{5}$ lends further weight to the concept of the pain of aortic dissection as a dynamic product of interrelated changes in intraluminal pressure, volume, wall stress and diameter.

It is important to consider that various factors may limit the ability to detect this clinical sign, including the inability to adequately position the patient, or other patient characteristics such as increased abdominal adiposity. In addition, there is a theoretical possibility that a transient increase in afterload may cause extension of the false lumen, which only serves to emphasise the importance of timely recognition of the clinical signnot only to prompt further definitive investigation but also to avoid further unnecessary abdominal palpation.

\section{Learning points}

The diagnosis of aortic dissection is often difficult and requires a high index of clinical suspicion.

- The clinical features of aortic dissection are dictated by the anatomy of the tear.

- The clinical phenomenon described here may be idiosyncratic, but also may potentially serve as a specific sign of acute aortic pathology. 
The diagnosis of aortic dissection requires a high index of clinical suspicion and is notoriously difficult due to the poor predictive qualities of the associated clinical features. The cost of missing the diagnosis is high and thus there exists the need for better clinical prediction criteria to enhance the detection of aortic pathology. The clinical phenomenon described here may be idiosyncratic, but also may potentially serve as a specific sign of acute aortic pathology. Further case reports and observational data will be useful in elucidating a clear pathophysiological link.

Contributors All authors have contributed to the writing and editing of this case report. TM identified the case and initially examined the patient in the Emergency Department of our institution. TM did the literature review and construction of the case report. MF guided the areas for discussion. Further discussion points were added by PJ, who also made some grammatical and syntax adjustments. MF edited the final draft.

Competing interests None declared.

Patient consent Obtained.

Provenance and peer review Not commissioned; externally peer reviewed.
Open Access This is an Open Access article distributed in accordance with the Creative Commons Attribution Non Commercial (CC BY-NC 4.0) license, which permits others to distribute, remix, adapt, build upon this work non-commercially, and license their derivative works on different terms, provided the original work is properly cited and the use is non-commercial. See: http://creativecommons.org/ licenses/by-nc/4.0/

(C) BMJ Publishing Group Ltd (unless otherwise stated in the text of the article) 2017. All rights reserved. No commercial use is permitted unless otherwise expressly granted.

\section{REFERENCES}

1 Hagan PG, Nienaber CA, Isselbacher EM, et al. The International Registry of Acute Aortic Dissection (IRAD): new insights into an old disease. JAMA 2000;283:897-903.

2 Armstrong WF, Bach DS, Carey LM, et al. Clinical and echocardiographic findings in patients with suspected acute aortic dissection. Am Heart J 1998;136:1051-60.

3 Cheng Z, Tan FPP, Riga CV, et al. Analysis of flow patterns in a patient-specific aortic dissection model. J Biomech Eng 2010;132:051007-9.

4 Karmonik C, Bismuth J, Shah DJ, et al. Computational study of haemodynamic effects of entry- and exit-tear coverage in a DeBakey type III aortic dissection: technical report. Eur J Vasc Endovasc Surg 2011;42:172-7.

5 Hunt WE, Wooley CF. The pulsatile pain of acute aortic dissection: a neurosurgeon's personal experience. Am Heart J 1996;132:1267-8.

Copyright 2017 BMJ Publishing Group. All rights reserved. For permission to reuse any of this content visit http://group.bmj.com/group/rights-licensing/permissions.

BMJ Case Report Fellows may re-use this article for personal use and teaching without any further permission.

Become a Fellow of BMJ Case Reports today and you can:

- Submit as many cases as you like

- Enjoy fast sympathetic peer review and rapid publication of accepted articles

- Access all the published articles

- Re-use any of the published material for personal use and teaching without further permission

For information on Institutional Fellowships contact consortiasales@bmjgroup.com

Visit casereports.bmj.com for more articles like this and to become a Fellow 